\title{
Adhesion receptors as therapeutic targets for circulating tumor cells
}

\author{
Jiahe Li and Michael R. King* \\ Department of Biomedical Engineering, Cornell University, Ithaca, NY, USA
}

\section{Edited by:}

Silvia Giordano, University of Torino, Italy

\section{Reviewed by:}

Maria Felice Brizzi, University of Torino, Italy

Guido Serini, University of Torino

School of Medicine, Italy

${ }^{*}$ Correspondence:

Michael R. King, Department of Biomedical Engineering, Cornell University, 205 Weill Hall, Ithaca, NY 14853, USA.

e-mail: mike.king@cornell.edu
Metastasis contributes to $>90 \%$ of cancer-associated mortality. Though primary tumors can be removed by surgical resection or chemo/radiotherapy, metastatic disease is a great challenge to treatment due to its systemic nature. As metastatic "seeds," circulating tumor cells (CTCs) are believed to be responsible for dissemination from a primary tumor to anatomically distant organs. Despite the possibility of physical trapping of CTCs in microvessels, recent advances have provided insights into the involvement of a variety of adhesion molecules on CTCs. Such adhesion molecules facilitate direct interaction with the endothelium in specific tissues or indirectly through leukocytes. Importantly, significant progress has been made in understanding how these receptors confer enhanced invasion and survival advantage during hematogenous circulation of CTCs through recruitment of macrophages, neutrophils, platelets, and other cells. This review highlights the identification of novel adhesion molecules and how blocking their function can compromise successful seeding and colonization of CTCs in new microenvironment. Encouraged by existing diagnostic tools to identify and isolate CTCs, strategic targeting of these adhesion molecules to deliver conventional chemotherapeutics or novel apoptotic signals is discussed for the neutralization of CTCs in the circulation.

Keywords: adhesion, receptors, CTCs, cancer therapy

\section{INTRODUCTION}

Circulating tumor cells (CTCs) are cells that leave a primary tumor and circulate in the blood. More than a century ago the Australian physician Thomas Ashworth first observed CTCs in the blood of a patient with metastatic cancer. He hypothesized that "the cancer itself being seen in the blood may tend to throw some light upon the mode of origin of multiple tumors existing in the same person." In the past decade, advancing technologies to detect and isolate CTCs have provided unique fluid biopsy information for prognosis, management of chemotherapy dosing and timing as well as monitoring the development of drug resistance over time (Nagrath et al., 2007; Lowes et al., 2011; Scher et al., 2011). Driven by these technologies, numerous clinical studies performed for breast, colon, prostate, and other epithelial cancers establish a clear connection between average CTC counts and overall survival rate before and during treatment (Cristofanilli et al., 2004, 2005; Hou et al., 2009; Criscitiello et al., 2010; Yalcin et al., 2010; Danila et al., 2011; Lianidou and Markou, 2011).

In contrast to the rapid development of tools for CTC detection and isolation, effective therapies that directly remove CTCs from the blood circulation are still underexplored. This is probably attributable to our limited understanding of the heterogeneity of CTCs: in most studies, CTCs are defined as being positive for epithelial cell adhesion molecule (EpCAM+) and cytokeratin 8, 18 , or $19(\mathrm{CK}+)$ and negative for CD45 (CD45-) (Allard et al., 2004). However, almost a third of patients with advanced breast, colorectal, and prostate cancers have CTCs that do not meet these criteria (Coumans et al., 2010). Despite the heterogeneity of CTC markers, some studies have shown that cancer stem cell (CSC) or stem-like cell (CSC-like) markers are frequently expressed by CTCs (Aktas et al., 2009; Theodoropoulos et al., 2010; Iinuma et al., 2011; Toloudi et al., 2011; Kasimir-Bauer et al., 2012; Wang et al., 2012). Such features are especially relevant for targeting CTCs as CSCs are believed to represent a subpopulation of cancer cells that drive the growth and progression of metastatic cancers (Ghiaur et al., 2012; Vermeulen et al., 2012).

The presence of CTCs in the circulation can in part explain a clinical observation that the removal of a primary tumor is often followed with distant metastasis and/or local recurrence. For example, it was estimated that $20-50 \%$ patients first diagnosed with primary breast cancer eventually developed metastatic disease in the past (Lu et al., 2009). In the case of hepatocellular carcinoma (HCC), liver transplantation is the best treatment for early-stage patients. Unfortunately, every year around $10 \%$ of recipients develop post-transplant HCC recurrence, which leads to death in almost all patients (Toso et al., 2011). To understand the molecular mechanism, Kim and colleagues developed a tumor self-seeding mouse model whereby the local recurrence mediated by CTCs was investigated using human colorectal, melanoma, and breast cancer cells. They found that tumor-derived IL-6 and IL-8 served as CTC attractants whereas the seeder CTCs highly expressed invasion-associated genes (MMP1, FSCN1, and CXCL1) to promote infiltration (Kim et al., 2009). This finding highlights a highly orchestrated process of local recurrence mediated by CTCs.

CTCs play a predominant role in the metastases to distant organs. In the blood circulation, CTCs are subject to a multitude of stresses including anchorage-dependent survival signaling, 
immuno-surveilance, and shear stress. For example, CTCs are deprived of integrin-dependent adhesion to extracellular matrix (ECM) components in comparison to nontransformed cells. Whereas such loss of anchorage induces apoptosis (anoikis) in normal cell types, CTCs are particularly resistant to anoikis by promoting PI3K/Akt proliferation signaling and expression of anti-apoptotic proteins such as BCL2 (Frisch and Ruoslahti, 1997; Guo and Giancotti, 2004). Notably, numerous research has demonstrated that CTCs do not mobilize in the circulation alone. Instead, through heterotypic interactions with endothelial cells and different types of haemopotoeic cells, CTCs acquire the potential to metastasize to distant organs (Figure 1). Therefore, such receptor-mediated adhesion can provide a unique opportunity for neutralizing CTCs either through the blockade of receptors or receptor-targeted drug delivery.

\section{THE BIOLOGY OF SELECTIN-MEDIATED HEMATOGENOUS METASTASIS}

Selectins are transmembrane glycoproteins which were initially found to bind specific glycoproteins on leukocytes. Three structurally related adhesion molecules, L-, E-, and P-selectin are composed of an N-terminal C-type lectin domain which confers specific, $\mathrm{Ca}^{2+}$-dependent carbohydrate-binding activity. It is followed by an epidermal growth factor (EGF)-like domain, a variable number of short consensus repeats domains $(2,6$, and 9 for L-, E-, and P-selectin, respectively), a single-pass transmembrane domain and a short intracellular C-terminal tail (Ley, 2003). Despite structural similarity, the three selectins have distinct tissue-specific expression and binding kinetics. L-selectin is constitutively expressed on the surface of almost all types of leukocytes and is cleaved from the cell surface upon activation with a variety of cytokines and chemokines (Grailer et al., 2009). In contrast, the expression of $\mathrm{E}$ - and P-selectin is inducible on vascular endothelial cells during inflammation. Whereas E-selectin depends on de novo mRNA synthesis, P-selectin is stored in Weibel-Palade bodies of endothelial cells. Additionally, platelets express $\mathrm{P}$-selectin which translocates from $\alpha$-granules upon platelet activation (Larsen et al., 1992).

The role of selectins in mediating the rolling and trafficking of neutrophils and monocytes to inflammation sites has been well studied. More recently, it has been proposed that CTCs adopt similar strategies to facilitate their initial entrapment in the vessels and subsequent extravasation. Köhler and colleagues provided the first in vivo evidence that $\mathrm{E}$ - and P-selectin are essential for colorectal cancer metastasis. They generated a transgenic immuno-compromised mouse with E- and P-selectin doubly knocked out. Compared to wild-type mice, the double knockout mice with subcutaneously implanted colon cancer cells showed lung metastases reduced in number by $84 \%$ (Kohler et al., 2010). In agreement with earlier in vitro studies, a model was proposed in which the sialylated fucosylated glycans decorated on transmembrane proteins or specific lipids of CTCs mediate the rolling and adhesion to selectin-expressing endothelial cells. The role of selectin ligands in mediating the hematogenous metastasis of CTCs has been reviewed extensively elsewhere (Konstantopoulos and Thomas, 2009; Geng et al., 2012). However, this section focuses on therapeutic interventions of selectin binding that have been explored for the prevention of metastasis.

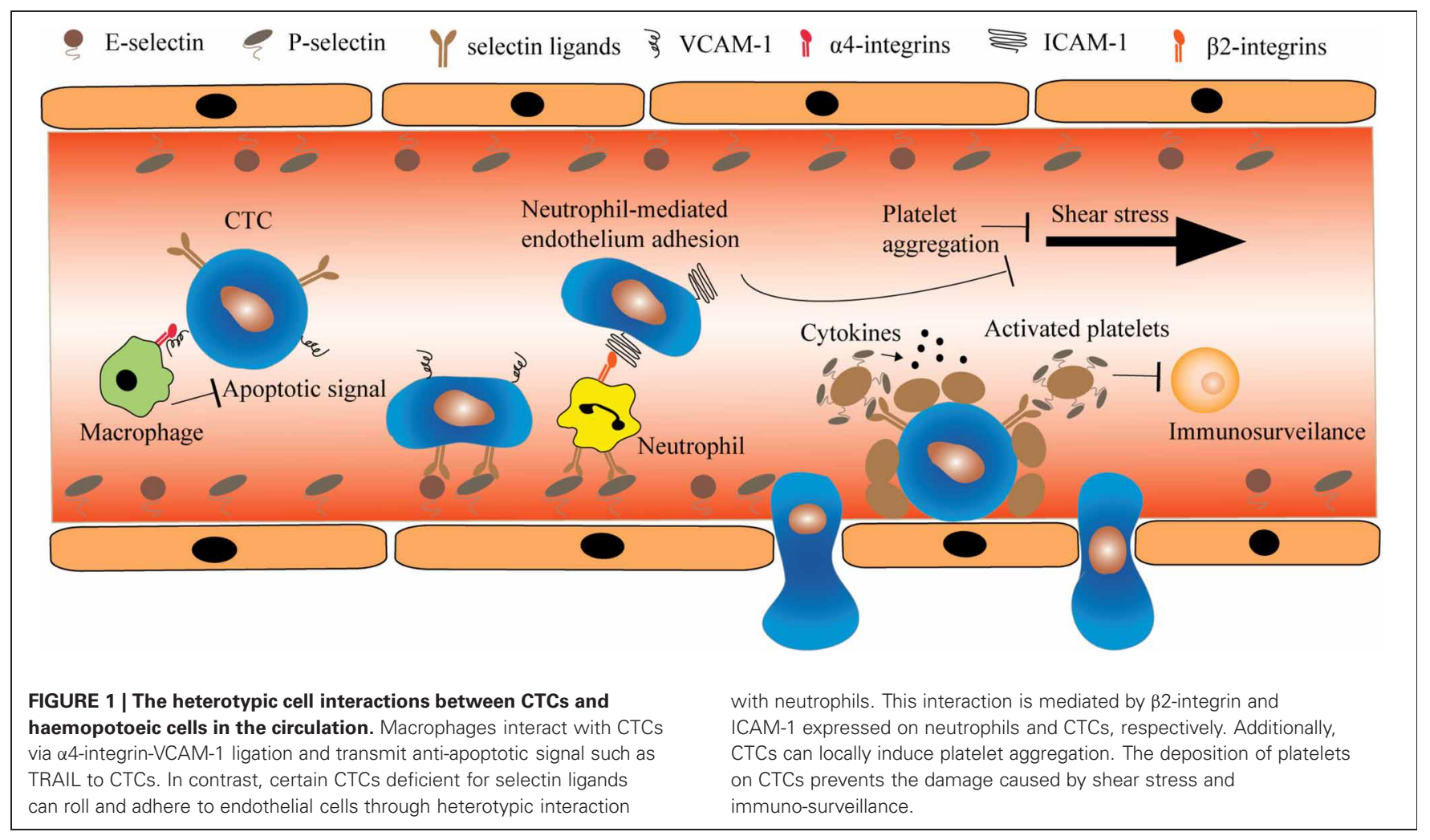




\section{CARBOHYDRATE-BASED INHIBITORS}

Given that all three selectins recognize sialylated fucosylated glycans such as $s L e^{x}$, the $s L e^{x}$ analogs have been shown to significantly prevent neutrophil accumulation and myocardial necrosis after ischemia and reperfusion in animal models (Buerke et al., 1994; Lefer et al., 1994; Zacharowski et al., 1999). This implies that the same analogs may be potent inhibitors for reducing CTC adhesion to endothelium. Shirota and colleagues investigated the inhibitory effect of a sLe ${ }^{\mathrm{x}}$ analog, GSC-150 on hepatic metastasis of human colon carcinoma in nude mice. They found that liver metastases were significantly attenuated when cancer cells were co-administered with GSC-150 (Shirota et al., 2001). In addition to $s L e^{\mathrm{x}}$ analogs, novel disaccharides have been generated which function as competitive substrate inhibitors for glycotransferases involved in the synthesis of $\mathrm{LLe}^{\mathrm{x}}$. To this end, a disaccharide compound was able to inhibit $\mathrm{sLe}^{\mathrm{x}}$ formation in human monocytic leukemia cells, U937. Its therapeutic effect was further studied in Lewis lung carcinoma in vivo where the experimental metastasis was significantly reduced through the decreased expression of $s^{\mathrm{x}} \mathrm{e}^{\mathrm{x}}$ (Brown et al., 2009). Nevertheless, strategies to abrogate $\mathrm{sLe}^{\mathrm{x}}$-selectin interaction must be considered carefully. Given the turnover rate of selectins or glycotransferases, such carbohydrates may not have a long-lasting inhibitory effect. Moreover, as $\mathrm{sLe}^{\mathrm{x}}$ is essential for directing neutrophils and lymphocytes to inflamed tissues, the chronic exposure to $\mathrm{sLe}^{\mathrm{x}}$ analogs or metabolic inhibitors can interfere with the normal inflammatory response. Therefore, investigations on the cellular sLe ${ }^{\mathrm{x}}$ synthesis that differentiate CTCs from leukocytes may provide more specific targeting of CTCs while reducing side effects.

\section{GENE SILENCING OF FUCOSYLTRANSFERASES IN CTCs}

As the key determinants of selectin ligands, sLe ${ }^{\mathrm{x}}$ and $s L e^{\mathrm{a}}$ are synthesized in the Golgi compartments by sequential actions of $\mathrm{N}$-acetylglucosaminyl-, galactosyl-, sialyl-, and fucosyltransferases. Of note is the terminal step of transferring fucose to $\mathrm{N}$-acetylglucosamine catalyzed by a family of fucosyltransferase genes (Hennet, 2002). At least nine FUT genes have been identified in the human genome among which FUT3, 4, 6, and 7 have been well characterized. They are redundant in the synthesis of sialyl lewis carbohydrates but display cell type-specific expression. FUT4 and FUT7 are mainly expressed in blood cell lineages and play a key role in the selectin ligand-mediated migration of leukocytes during the inflammatory response (Weninger et al., 2000). In contrast, FUT3 and FUT6 are more associated with the progression of cancers, including breast (Matsuura et al., 1998; Ding and Zheng, 2004), prostate (Barthel et al., 2008), lung (Ogawa et al., 1996), liver (Wang et al., 2003), and gastric cancer (Petretti et al., 1999). To exploit the therapeutic potential of targeting fucosyltransferases, our laboratory first confirmed that hematopoietic cell lines (HL60 and KG1a) predominantly express FUT4 and FUT7 whereas prostate cancer cell line MDA PCa2b mainly expresses FUT3. Next, siRNA against FUT3 reduced sLe ${ }^{\mathrm{x}}$ expression on prostate cancer cells and significantly inhibited cell rolling and adhesion to a E-selectinfunctionalized surface under physiological flow. In addition, the siRNA was able to impair cell growth which may not be directly associated with $s L e^{\mathrm{x}}$. In fact, two recent studies revealed that the overexpression of FUT4 and FUT6 promoted cell growth by elevating intracellular Akt phosphorylation and suppressing the cyclin-dependent kinase inhibitor p21 in epidermoid carcinoma and HCC cells, respectively, (Yang et al., 2010; Guo et al., 2012). Therefore, silencing FUTs via siRNA can simultaneously inhibit the adhesion and clonal expansion of CTCs in the blood circulation. To apply this strategy in vivo, P-selectin-based liposome nanoparticles recently developed in our laboratory can be used to encapsulate siRNAs against FUTs (Huang and King, 2009). Although P-selectin recognizes both circulating leukocytes and CTCs, siRNAs against FUTs exclusively expressed in CTCs provide additional targeting specificity.

\section{THERAPEUTIC ABROGATION OF CTC-HEMATOPOIETIC CELL INTERACTION}

It is estimated that less than $0.01 \%$ of CTCs shed from a primary tumor can survive to produce clinically relevant metastases (Joyce and Pollard, 2009). This suggests that the process of metastasis by CTCs is largely inefficient. Whereas the mechanisms underlying such high rates of attrition remain poorly understood, recent studies identified two important cell adhesion molecules involved in the physical interactions of CTCs with hematopoietic cells: vascular cell adhesion molecule-1 (VCAM-1) and intercellular adhesion molecule-1 (ICAM-1). Such interactions facilitate CTCs in several aspects: (1) survival in the circulation, (2) initial arrest and subsequent extravasation, and (3) eventual growth into overt metastasis (Chambers et al., 2002).

The transmembrane protein VCAM-1 was originally thought to be presented exclusively on endothelial cells in response to tumor necrosis factor-alpha (TNF- $\alpha$ ) and interleukin-1 (IL-1) during inflammation (Coussens and Werb, 2002). It binds to the leukocyte integrins $\alpha 4 \beta 1$ and $\alpha 4 \beta 7$ on circulating monocytes, granulocytes, and lymphocytes (Osborn et al., 1989; Elices et al., 1990). However, aberrant expression of VCAM-1 was found to be one of 18 signature genes associated with lung metastasis of breast cancer in both experimental mouse models and patients (Minn et al., 2005). Chen and colleagues found that VCAM-1 on breast cancer CTCs tethered to metastasisassociated macrophages which express $\alpha 4$-integrins. Clustering of VCAM-1 on CTCs induces Akt activation and protects CTCs from proapoptotic cytokines such as TNF-related apoptosis-inducing ligand (TRAIL). Notably, either silencing VCAM-1 expression by siRNA or blocking antibody against $\alpha 4$-integrins abolished the pro-survival effect of VCAM-1 (Chen et al., 2011). In addition, VCAM-1 was also recently found to be associated with bone metastasis in breast cancer. Prior to this study, a bone-metastatic gene signature including CXCR4, IL11, CTGF, MMP1, and OPN was identified through the reiterative selection of human breast cancer cells MDA-MB-231 in immuno-compromised mice (Kang et al., 2003). However, by studying a subpopulation of MDA-MB231 which experienced a long dormancy prior to bone metastasis, $\mathrm{Lu}$ and colleagues discovered that the aberrant expression of VCAM-1 engaged $\alpha 4$-integrins on monocytic osteoclast progenitors to promote the local osteolytic activity in bone ( $\mathrm{Lu}$ et al., 2011). This mouse study was further corroborated by comparing VCAM-1 levels between clinical early and late recurrences of bone 
metastases. Higher VCAM-1 was significantly associated with early relapse (Wang et al., 2005).

Like VCAM-1, ICAM-1 is another cell surface glycoprotein which is typically expressed on endothelial cells in response to TNF- $\alpha$ or IL-1 in inflammation. However, the constitutive expression of ICAM-1 on CTCs was found to promote tumor cell transendothelial migration in melanoma (Huh et al., 2010), pancreatic (Roland et al., 2010), and breast cancers (Wu et al., 2001). To understand this mechanism, in vitro biophysical studies demonstrated that under physiological shear stress ICAM-1 on melanoma CTCs promotes the heterotypic interaction with neutrophils by engaging $\beta 2$-integrins (CD11a and CD11b) (Hoskins and Dong, 2006; Liang et al., 2008). Moreover, as neutrophils have selectin ligands, such heterotypic interaction facilitates the adhesion and extravasation of melanoma CTCs which otherwise bind inefficiently to the endothelium (Slattery and Dong, 2003; Liang et al., 2005). Later, our laboratory studied the physical mechanisms of retinoblastoma metastasis. Whereas human RB cell lines RB143 and WERI-Rb27 do not express E-selectin ligands, they can be recruited to an E-selectin-coated surface through attachment to activated neutrophils. This interaction is also mediated by ICAM-1: $\beta 2$-integrin (Geng et al., 2010). To test the involvement of this heterotypic interaction in vivo, Jin Huh and colleagues compared the lung metastases of human melanoma cells injected alone or in combination with human neutrophils (Huh et al., 2010). They found that human neutrophils enhanced CTCs retention in the lung by three-fold. To dissect the molecular mechanism, the cytokine interleukin-8 (IL-8) was found to be a key determinant expressed by melanoma cells to attract neutrophils. IL- 8 secretion increased $\beta 2$-integrin levels on neutrophils and heterotypic aggregation between ICAM-1-positive CTCs and neutrophils. Importantly, siRNA against IL- 8 impaired transendothelial migration and lung metastasis by $\sim 50 \%$. In addition to targeting IL-8 as a therapeutic approach, it is possible that blocking antibodies against ICAM-1 or $\beta 2$-integrins may be also effective (Rosette et al., 2005).

\section{PLATELETS AGGRAVATE CTC METASTASIS}

Platelets are anuclear cytoplasmic bodies released from megakaryocytes in the bone marrow. It is estimated that one liter of blood contains about 400 billion circulating platelets. The primary role of platelets is to maintain haemostasis. This is initiated via platelet activation which results in adhesion and release of a multitude of bioactive factors from platelet granules. In addition to haemostatic regulation, platelets have long been believed to play a critical role in cancer metastasis through the enhancement of CTC survival and adhesion to the endothelium in the circulation. The involvement of platelets in cancer was first recorded in the mid-nineteenth century by the French clinician Armand Trousseau. He diagnosed patients with migratory thrombophlebitis caused by an occult visceral carcinoma (Gupta and Massague, 2004). In fact, preclinical studies in genetic knockout mice provide evidence that upon immediate entry into the circulation, tissue factor highly expressed by CTCs can signal downstream through FVIIa and FXa to activate a coagulation cascade leading to thrombin generation, fibrin deposition, and platelet aggregation around CTCs (Camerer et al., 2004; Kasthuri et al., 2009; Liu et al., 2011). Such a "platelet cloak" is known to initially trap tumor cells in microvessels (Borsig et al., 2001).

Several mechanisms of platelets in promoting CTC survival have been proposed based on preclinical experiments in mice using a variety of mouse and human carcinoma cell lines. Aggregation of platelets around CTCs protect against immunemediated clearance of CTCs largely mediated by natural killer (NK) cells. The potential of CTCs to induce platelet aggregation correlates with their enhanced metastatic potential. Bernhard Nieswandt and colleagues demonstrated for the first time that platelets directly impair NK lysis of tumor cells in vitro and in vivo. In a mouse model of experimental metastasis, they found that tumor seeding in the lung was reduced when platelets were depleted from the host (Nieswandt et al., 1999). Further studies reveal that CTC evasion of NK cells is not merely attributed to physical shielding of platelets. NK cell activity is guided by the principles of "missing-self" and "induced-self," which imply that cells lacking expression of MHC class I (missing-self) and/or a stress-induced expression of ligands for activating NK receptors (induced-self) are preferentially recognized and eliminated (Moretta and Moretta, 2004; Lanier, 2005). While CTCs are often associated with lack of MHC class I, platelets can disrupt "missing self" recognition of NK cells by grafting MHC I class onto CTCs (Placke et al., 2012). Furthermore, platelet-derived transforming growth factor $\beta$ (TGF- $\beta$ ) can downregualte the activating immunoreceptor NK group 2, member D (NKG2D) on NK cells (Kopp et al., 2009).

\section{THERAPEUTIC INTERVENTION OF PLATELET ADHESION TO CTCs}

As the blood clotting pathway contributes to platelet adhesion to CTCs, a variety of anticoagulation agents have been tested either alone or together with conventional cancer drugs in preclinical mouse models. Using an experimental metastasis mouse model, Amirkhosravi and colleagues found that the intravenous injection of recombinant mouse tissue factor pathway inhibitor (TFPI) immediately before inoculation of tumor cells reduced metastasis by $83 \%$ (Amirkhosravi et al., 2002, 2007). Similarly, Cilostazol, a selective inhibitor of phosphodiesterase 3 with anticoagulatory and profibrinolytic effects completely abolished the complex formation of 4T1 tumor cells in the presence of activated platelets in vitro. In a spontaneous model of mouse $4 \mathrm{~T} 1$ breast cancer, the injection of Cilostazol six hours before tumor inoculation reduced pulmonary metastasis by $55 \%$. As platelet aggregation and adhesion to CTCs enhance their survival in the blood circulation, abrogation of the coagulation cascade renders CTCs susceptible to cancer drugs. Wenzel and colleagues invented dual liposomes simultaneously containing the hemostatic inhibitor dipyridamole and the anticancer drug perifosine. The liposomes caused a $90 \%$ reduction in the number of lung metastases in a mouse experimental metastasis model (Wenzel et al., 2010).

Despite the fact that anticoagulants hold promise for the prevention of metastasis, they may impair the normal hemostatic function of platelets in the presence of bleeding. Platelet intervention therapies against metastasis must exhibit certain specificity for tumor cell-platelet interactions. Therefore, direct inhibition of platelet adhesion to CTCs may minimize the cardiovascular side effect of anticoagulants. To this goal, heparin and chemically 
modified heparins have been shown to attenuate the metastasis of human colon carcinoma in a mouse xenograft model (Koenig et al., 1998; Stevenson et al., 2005; Hostettler et al., 2007). The anti-metastatic effect of heparin was initially believed to associate with its anticoagulant activity. Later it was found that competitive binding of heparin to P-selectin on activated platelets abolishes interaction with $\mathrm{P}$-selectin ligands such as sialylated fucosylated mucins expressed on human colon carcinoma cells (Wei et al., 2004; Stevenson et al., 2005; Hostettler et al., 2007; Lee et al., 2008). As the anticoagulant activity of heparin is undesirable in the context of blocking CTC-platelet interactions, polysaccharides isolated from certain sea plants and fungi have shown enhanced inhibition of P-selectin binding without anticoagulant effect. A fucosylated chondroitin sulfate (FucCS) from sea cucumber is 4-8 fold more potent than heparin in the inhibition of LS180 carcinoma cell attachment to immobilized P- and L-selectin. Moreover, administration of FucCS $30 \mathrm{~min}$ prior to mouse colon carcinoma MC-38 injection is associated with 2-fold CTC-platelet aggregates than heparin in the mouse lung. Long-term experiment reveals that FuCS significantly reduced lung metastatic foci by $80 \%$ compared to saline control (Borsig et al., 2007).

\section{THERAPEUTIC BLOCKAGE OF PLATELET SIGNALING TO CTCs}

Certain CTCs express epithelial markers such as EpCAM and cytokeratins, suggesting that the epithelial-mesenchymal transition (EMT) is not necessarily required for CTCs to access the blood circulation. Instead, a transient contact between platelets and CTCs in the blood circulation is sufficient to induce an EMT gene signature and invasive behavior primarily through the platelet-secreted transforming growth factor- $\beta 1$ (TGF- $\beta 1$ ) (Labelle et al., 2011). Recently, a small molecule inhibitor, SD208 , has been shown to block the TGF- $\beta$ receptor I kinase (T $\beta R I)$ activity. SD-208 successfully prevented the development of TGF- $\beta$-induced bone metastases and decreased the progression of established osteolytic lesions in a melanoma mouse model (Mohammad et al., 2011). Therefore, SD-208 possibly represents a viable therapeutic to inhibit platelet-derived TGF- $\beta$ signaling. In addition to TGF- $\beta$, platelet $\alpha$-granules store abundant proangiogenic factors including vascular endothelial growth factor (VEGF), basic fibroblast growth factor (bFGF), EGF, platelet-derived growth factor (PDGF) and insulin-like growth factor-1 and -2 (IGF-1 and -2) (Sierko and Wojtukiewicz, 2007). Given that inhibitors for the proangiogenic factors or their counter-receptors are available as cancer drugs in the treatment of solid tumors (Roberts et al., 2005; Moreira et al., 2007; Weroha and Haluska, 2008), it is possible that such inhibitors can be used as adjuvant therapies in the context of targeting CTCs.

\section{NOVEL SELECTIN-BASED TARGETING DRUG DELIVERY TO CTCs}

Over the past several years, our laboratory has developed a biomimetic approach to isolate CTCs using a selectinimmobilized microtube device (Hughes and King, 2010; Hughes et al., 2012a,b). Two factors are responsible for the efficient capture of CTCs by this device. First, the ability of selectins to mediate the rapid tethering and rolling of leukocytes or CTCs under shear is attributed to the fast kinetics between selectins and selectin ligands (Lawrence and Springer, 1991; Wild et al., 2001). The fact that cells can be enriched under flow conditions significantly enhances the sample processing rate. Second, the microtube allows for the margination of CTCs toward the wall to interact with immobilized selectins. This margination effect has been well characterized when leukocytes circulate in a flowdependent interaction with red blood cells (Bagge et al., 1983; Goldsmith and Spain, 1984; Iadocicco et al., 2002).

Inspired by isolating CTCs under flow conditions, we translated the device to a unique drug delivery platform whereby the immobilization of drug molecules on the surface creates a high localized concentration. One device immobilizes E-selectinconjugated liposomes onto the surface of a blood-compatible microrenathane (MRE) tube. After encapsulating doxorubicin (DOX), the liposomes could specifically capture cells from the flow and efficiently deliver DOX into adherent cells. Moreover, a halloysite nanotube (HNT)-coated surface further enhanced the targeting and killing of cancer cells (Figures 2A,B), which was attributed to the increased surface area for both E-selectin and DOX.

To provide more specificity to CTCs, two additional approaches have been pursued by our laboratory. One approach was to functionalize the microtube surface with both E-selectin and antibodies against epithelial markers such as EpCAM. Such additional antibodies were able to discriminate between leukocytes and CTCs when cells roll on the surface (Hughes et al., 2012a). The second approach was to replace DOX with molecules that are tumor-specific, such as TRAIL. TRAIL holds promise as a tumor-specific therapeutic as it selectively induces an apoptotic signal by binding to death receptors on the cell surface (Koschny et al., 2007; Wang, 2008). To this end, our lab developed a death receptor-mediated apoptosis device to deliver apoptosis signal to captured CTCs (Figure 3A). Notably, with TRAIL and E-selectin on the surface, one hour of rolling exposure was sufficient to kill 30\% of leukemia cells (HL60) whereas the viability of normal mononuclear cells was not affected (Figures 3B,C) (Rana et al., 2009, 2012).

\section{CONCLUDING REMARIKS}

In haematogenous metastasis, a primary tumor sheds CTCs into the blood circulation which comprise a population of carcinoma cells that can exhibit CSC or CSC-like features. Two hypotheses have been proposed regarding how CTCs establish the initial contact with endothelial cells prior to metastasis. The physical trapping hypothesis is based on the fact that the luminal diameter of capillaries is $\sim 8 \mu \mathrm{m}$ while the diameter of CTCs ranges from 20 to $30 \mu \mathrm{m}$. Thus, CTCs can be simply mechanically trapped in the capillary bed during their first pass through the circulation (Valastyan and Weinberg, 2011). However, the findings that certain CTCs display organ-specific tropism (e.g., bone metastases in breast and prostate cancer) challenge this hypothesis (Kang et al., 2003; Barthel et al., 2008). In fact, by displaying selectin ligands on their surface, CTCs in certain cancers acquire the ability to roll and adhere to the endothelium and subsequently exit from the circulation. The identification of selectin-dependent 

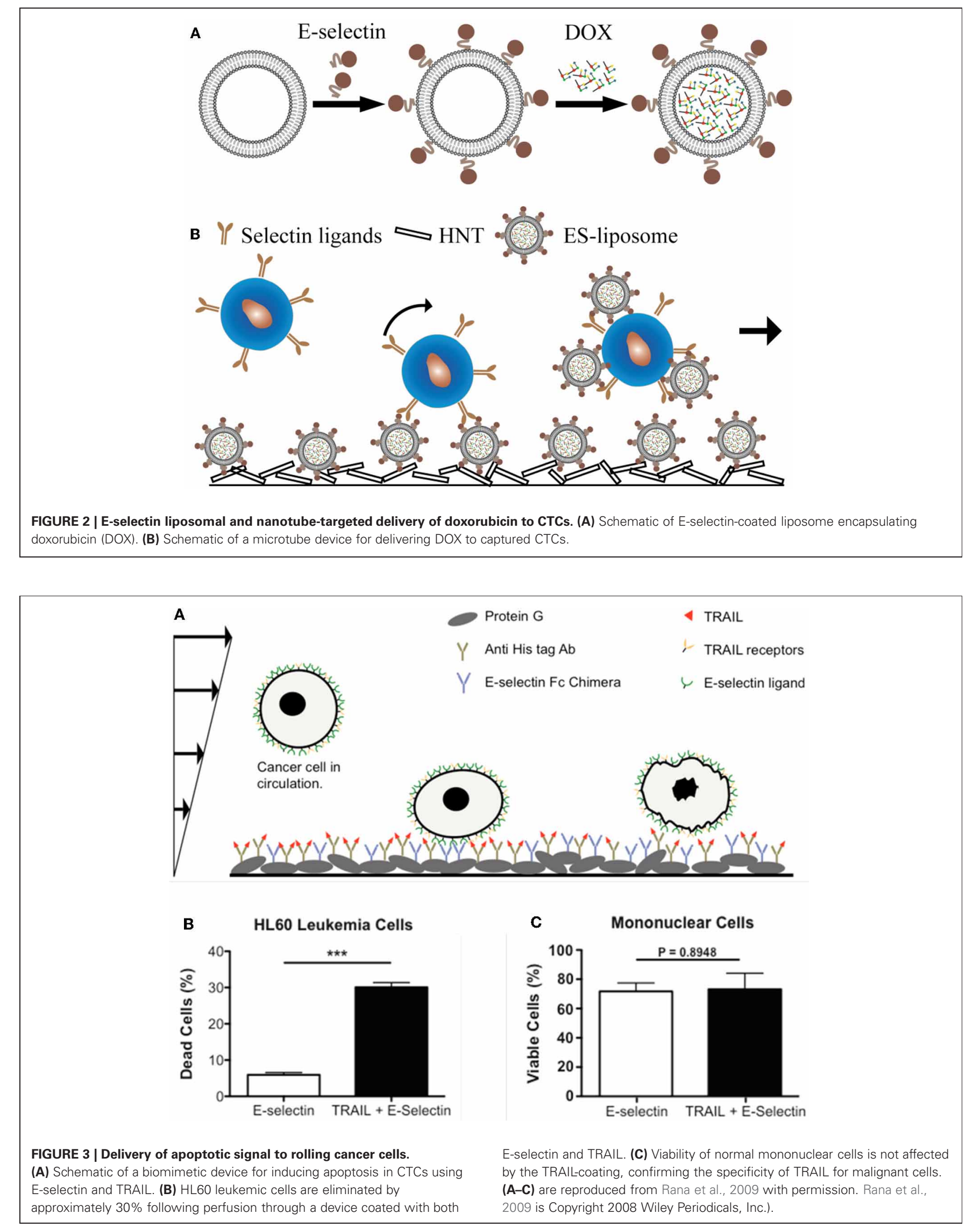
metastasis has made it possible to develop a range of antagonists against selectins or selectin ligands. Such antagonists have proven efficient in reducing experimental metastases in many mouse cancer models. However, they may impair the selectin-dependent trafficking of leukocytes to inflamed areas during the normal inflammatory response. The gene silencing of specific FUTs may confer specificity to CTCs as different FUTs have been shown to differentially express in CTCs versus leukocytes (Yin et al., 2010). Nevertheless, the CTC-endothelium interaction alone is not sufficient for CTCs to overcome damages incurred by hemodynamic shear forces and immuno-surveillance. The survival of CTCs in the blood circulation also depends on the interactions with haemopoetic cells such as macrophages, neutrophils, and platelets which require distinct adhesion receptors. Though the abrogation of individual adhesion receptors has shown promising results in a variety of mouse cancer models, it may be clinically relevant to develop a cocktail therapy which simultaneously targets multiple interactions between CTCs and other cell types.

\section{ACKNOWLEDGMENTS}

This work was supported by NIH Grant No. CA143876 to Michael R. King.

\section{REFERENCES}

Aktas, B., Tewes, M., Fehm, T., Hauch, S., Kimmig, R., and Kasimir-Bauer, S. (2009). Stem cell and epithelialmesenchymal transition markers are frequently overexpressed in circulating tumor cells of metastatic breast cancer patients. Breast Cancer Res. 11, R46.

Allard, W. J., Matera, J., Miller, M. C., Repollet, M., Connelly, M. C., Rao, C., Tibbe, A. G., Uhr, J. W., and Terstappen, L. W. (2004). Tumor cells circulate in the peripheral blood of all major carcinomas but not in healthy subjects or patients with nonmalignant diseases. Clin. Cancer Res. 10, 6897-6904.

Amirkhosravi, A., Meyer, T., Amaya, M., Davila, M., Mousa, S. A., Robson, T., and Francis, J. L. (2007). The role of tissue factor pathway inhibitor in tumor growth and metastasis. Semin. Thromb. Hemost. 33, 643-652.

Amirkhosravi, A., Meyer, T., Chang, J. Y., Amaya, M., Siddiqui, F., Desai, H., and Francis, J. L. (2002). Tissue factor pathway inhibitor reduces experimental lung metastasis of B16 melanoma. Thromb. Haemost. 87, 930-936.

Bagge, U., Blixt, A., and Strid, K. G. (1983). The initiation of postcapillary margination of leukocytes: studies in vitro on the influence of erythrocyte concentration and flow velocity. Int. J. Microcirc. Clin. Exp. 2, 215-227.

Barthel, S. R., Gavino, J. D., Wiese, G. K., Jaynes, J. M., Siddiqui, J., and Dimitroff, C. J. (2008). Analysis of glycosyltransferase expression in metastatic prostate cancer cells capable of rolling activity on microvascular endothelial (E)-selectin. Glycobiology 18, 806-817.

Borsig, L., Wang, L., Cavalcante, M. C., Cardilo-Reis, L., Ferreira, P. L., Mourao, P. A., Esko, J. D., and Pavao, M. S. (2007). Selectin blocking activity of a fucosylated chondroitin sulfate glycosaminoglycan from sea cucumber. Effect on tumor metastasis and neutrophil recruitment. J. Biol. Chem. 282, 14984-14991.

Borsig, L., Wong, R., Feramisco, J., Nadeau, D. R., Varki, N. M., and Varki, A. (2001). Heparin and cancer revisited: mechanistic connections involving platelets, P-selectin, carcinoma mucins, and tumor metastasis. Proc. Natl. Acad. Sci. U.S.A. 98, 3352-3357.

Brown, J. R., Yang, F., Sinha, A., Ramakrishnan, B., Tor, Y., Qasba, P. K., and Esko, J. D. (2009). Deoxygenated disaccharide analogs as specific inhibitors of beta1-4galactosyltransferase 1 and selectinmediated tumor metastasis. J. Biol. Chem. 284, 4952-4959.

Buerke, M., Weyrich, A. S., Zheng, Z., Gaeta, F. C., Forrest, M. J., and Lefer, A. M. (1994). Sialyl Lewisx-containing oligosaccharide attenuates myocardial reperfusion injury in cats. J. Clin. Invest. 93, 1140-1148.

Camerer, E., Qazi, A. A., Duong, D. N., Cornelissen, I., Advincula, R., and Coughlin, S. R. (2004). Platelets, protease-activated receptors, and fibrinogen in hematogenous metastasis. Blood 104, 397-401.

Chambers, A. F., Groom, A. C., and Macdonald, I. C. (2002). Dissemination and growth of cancer cells in metastatic sites. Nat. Rev. Cancer 2, 563-572.

Chen, Q., Zhang, X. H., and Massague, J. (2011). Macrophage binding to receptor VCAM-1 transmits survival signals in breast cancer cells that invade the lungs. Cancer Cell 20, 538-549.

Coumans, F. A., Doggen, C. J., Attard, G., De Bono, J. S., and Terstappen, L. W. (2010). All circulating EpCAM+CK+CD45objects predict overall survival in castration-resistant prostate cancer. Ann. Oncol. 21, 1851-1857.
Coussens, L. M., and Werb, Z. (2002). Inflammation and cancer. Nature 420, 860-867.

Criscitiello, C., Sotiriou, C., and Ignatiadis, M. (2010). Circulating tumor cells and emerging blood biomarkers in breast cancer. Curr. Opin. Oncol. 22, 552-558.

Cristofanilli, M., Budd, G. T., Ellis, M. J., Stopeck, A., Matera, J., Miller, M. C., Reuben, J. M., Doyle, G. V., Allard, W. J., Terstappen, L. W., and Hayes, D. F. (2004). Circulating tumor cells, disease progression, and survival in metastatic breast cancer. N. Engl. J. Med. 351, 781-791.

Cristofanilli, M., Hayes, D. F., Budd, G. T., Ellis, M. J., Stopeck, A., Reuben, J. M., Doyle, G. V., Matera, J., Allard, W. J., Miller, M. C., Fritsche, H. A., Hortobagyi, G. N., and Terstappen, L. W. (2005). Circulating tumor cells: a novel prognostic factor for newly diagnosed metastatic breast cancer. $J$. Clin. Oncol. 23, 1420-1430.

Danila, D. C., Fleisher, M., and Scher, H. I. (2011). Circulating tumor cells as biomarkers in prostate cancer. Clin. Cancer Res. 17, 3903-3912.

Ding, K. F., and Zheng, S. (2004) [Study on relationship of fucosyltransferase gene types in breast cancer with metastasis and prognosis]. Zhonghua Wai Ke Za Zhi 42, 546-550.

Elices, M. J., Osborn, L., Takada, Y., Crouse, C., Luhowskyj, S., Hemler, M. E., and Lobb, R. R. (1990). VCAM-1 on activated endothelium interacts with the leukocyte integrin VLA-4 at a site distinct from the VLA-4/fibronectin binding site. Cell 60, 577-584.

Frisch, S. M., and Ruoslahti, E. (1997). Integrins and anoikis. Curr. Opin. Cell Biol. 9, 701-706.

Geng, Y., Marshall, J. R., and King, M. R. (2012). Glycomechanics of the metastatic cascade: tumor cellendothelial cell interactions in the circulation. Ann. Biomed. Eng. 40, 790-805.

Geng, Y., Narasipura, S., Seigel, G. M., and King, M. R. (2010). Vascular recruitment of human retinoblastoma cells by multi-cellular adhesive interactions with circulating leukocytes. Cell. Mol. Bioeng. 3, 361-368.

Ghiaur, G., Gerber, J. M., Matsui, W., and Jones, R. J. (2012). Cancer stem cells: relevance to clinical transplantation. Curr. Opin. Oncol. 24, 170-175.

Goldsmith, H. L., and Spain, S. (1984). Margination of leukocytes in blood flow through small tubes. Microvasc. Res. 27, 204-222.

Grailer, J. J., Kodera, M., and Steeber, D. A. (2009). L-selectin: role in regulating homeostasis and cutaneous inflammation. J. Dermatol. Sci. 56, 141-147.

Guo, Q., Guo, B., Wang, Y., Wu, J., Jiang, W., Zhao, S., Qiao, S., and Wu, Y. (2012). Functional analysis of alpha1, 3/4-fucosyltransferase VI in human hepatocellular carcinoma cells. Biochem. Biophys. Res. Commun. 417, 311-317.

Guo, W., and Giancotti, F. G. (2004). Integrin signalling during tumour progression. Nat. Rev. Mol. Cell Biol. 5, 816-826.

Gupta, G. P., and Massague, J. (2004). Platelets and metastasis revisited: a novel fatty link. J. Clin. Invest. 114, 1691-1693.

Hennet, T. (2002). The galactosyltransferase family. Cell. Mol. Life Sci. 59, 1081-1095.

Hoskins, M. H., and Dong, C. (2006). Kinetics analysis of binding between melanoma cells and neutrophils. Mol. Cell. Biomech. 3, 79-87.

Hostettler, N., Naggi, A., Torri, G., Ishai-Michaeli, R., Casu, B., Vlodavsky, I., and Borsig, L. (2007). P-selectin- and heparanasedependent antimetastatic activity of non-anticoagulant heparins. FASEB J. 21, 3562-3572.

Hou, J. M., Greystoke, A., Lancashire, L., Cummings, J., Ward, T., Board, 
R., Amir, E., Hughes, S., Krebs, M., Hughes, A., Ranson, M., Lorigan, P., Dive, C., and Blackhall, F. H. (2009). Evaluation of circulating tumor cells and serological cell death biomarkers in small cell lung cancer patients undergoing chemotherapy. Am. J. Pathol. 175, 808-816.

Huang, Z., and King, M. R. (2009). An immobilized nanoparticlebased platform for efficient gene knockdown of targeted cells in the circulation. Gene Ther. 16, 1271-1282.

Hughes, A. D., and King, M. R. (2010). Use of naturally occurring halloysite nanotubes for enhanced capture of flowing cells. Langmuir 26, 12155-12164.

Hughes, A. D., Mattison, J., Western, L. T., Powderly, J. D., Greene, B. T., and King, M. R. (2012a). Microtube device for selectin-mediated capture of viable circulating tumor cells from blood. Clin. Chem. 58, 846-853.

Hughes, A. D., Mattison, J., Powderly, J. D., Greene, B. T., and King, M. R. (2012b). Rapid isolation of viable circulating tumor cells from patient blood samples. J. Vis. Exp. pii: 4248.

Huh, S. J., Liang, S., Sharma, A., Dong, C., and Robertson, G. P. (2010). Transiently entrapped circulating tumor cells interact with neutrophils to facilitate lung metastasis development. Cancer Res. 70, 6071-6082.

Iadocicco, K., Monteiro, L. H., and Chaui-Berlinck, J. G. (2002). A theoretical model for estimating the margination constant of leukocytes. BMC Physiol. 2, 3.

Iinuma, H., Watanabe, T., Mimori, K., Adachi, M., Hayashi, N., Tamura, J., Matsuda, K., Fukushima, R., Okinaga, K., Sasako, M., and Mori, M. (2011). Clinical significance of circulating tumor cells, including cancer stem-like cells, in peripheral blood for recurrence and prognosis in patients with Dukes' stage B and C colorectal cancer. J. Clin. Oncol. 29, 1547-1555.

Joyce, J. A., and Pollard, J. W. (2009). Microenvironmental regulation of metastasis. Nat. Rev. Cancer 9, 239-252.

Kang, Y., Siegel, P. M., Shu, W., Drobnjak, M., Kakonen, S. M., Cordon-Cardo, C., Guise, T. A., and Massague, J. (2003). A multigenic program mediating breast cancer metastasis to bone. Cancer Cell 3, 537-549.

Kasimir-Bauer, S., Hoffmann, O., Wallwiener, D., Kimmig, R., and Fehm, T. (2012). Expression of stem cell and epithelial-mesenchymal transition markers in primary breast cancer patients with circulating tumor cells. Breast Cancer Res. 14, R15.

Kasthuri, R. S., Taubman, M. B., and Mackman, N. (2009). Role of tissue factor in cancer. J. Clin. Oncol. 27, 4834-4838.

Kim, M. Y., Oskarsson, T., Acharyya, S., Nguyen, D. X., Zhang, X. H., Norton, L., and Massague, J. (2009). Tumor self-seeding by circulating cancer cells. Cell 139, 1315-1326.

Koenig, A., Norgard-Sumnicht, K., Linhardt, R., and Varki, A. (1998). Differential interactions of heparin and heparan sulfate glycosaminoglycans with the selectins. Implications for the use of unfractionated and low molecular weight heparins as therapeutic agents. J. Clin. Invest. 101, 877-889.

Kohler, S., Ullrich, S., Richter, U., and Schumacher, U. (2010). E-/P-selectins and colon carcinoma metastasis: first in vivo evidence for their crucial role in a clinically relevant model of spontaneous metastasis formation in the lung. Br. J. Cancer 102, 602-609.

Konstantopoulos, K., and Thomas, S. N. (2009). Cancer cells in transit: the vascular interactions of tumor cells. Annu. Rev. Biomed. Eng. 11, 177-202.

Kopp, H. G., Placke, T., and Salih, H. R. (2009). Platelet-derived transforming growth factor-beta downregulates NKG2D thereby inhibiting natural killer cell antitumor reactivity. Cancer Res. 69, 7775-7783.

Koschny, R., Walczak, H., and Ganten, T. M. (2007). The promise of TRAIL-potential and risks of a novel anticancer therapy. J. Mol. Med. (Berl.) 85, 923-935.

Labelle, M., Begum, S., and Hynes, R. O. (2011). Direct signaling between platelets and cancer cells induces an epithelial-mesenchymal-like transition and promotes metastasis. Cancer Cell 20, 576-590.

Lanier, L. L. (2005). NK cell recognition. Annu. Rev. Immunol. 23, 225-274.

Larsen, G. R., Sako, D., Ahern, T. J., Shaffer, M., Erban, J., Sajer, S. A., Gibson, R. M., Wagner, D. D., Furie, B. C., and Furie, B. (1992). P-selectin and E-selectin. Distinct but overlapping leukocyte ligand specificities. J. Biol. Chem. 267, 11104-11110.

Lawrence, M. B., and Springer, T. A. (1991). Leukocytes roll on a selectin at physiologic flow rates: distinction from and prerequisite for adhesion through integrins. Cell 65, 859-873.
Lee, D. Y., Park, K., Kim, S. K., Park, R. W., Kwon, I. C., Kim, S. Y., and Byun, Y. (2008). Antimetastatic effect of an orally active heparin derivative on experimentally induced metastasis. Clin. Cancer Res. 14, 2841-2849.

Lefer, D. J., Flynn, D. M., Phillips, M. L., Ratcliffe, M., and Buda, A. J. (1994). A novel sialyl LewisX analog attenuates neutrophil accumulation and myocardial necrosis after ischemia and reperfusion. Circulation 90, 2390-2401.

Ley, K. (2003). The role of selectins in inflammation and disease. Trends Mol. Med. 9, 263-268.

Liang, S., Fu, C., Wagner, D., Guo, H., Zhan, D., Dong, C., and Long, M. (2008). Two-dimensional kinetics of beta 2-integrin and ICAM-1 bindings between neutrophils and melanoma cells in a shear flow. Am. J. Physiol. Cell Physiol. 294, C743-C753.

Liang, S., Slattery, M. J., and Dong, C. (2005). Shear stress and shear rate differentially affect the multistep process of leukocyte-facilitated melanoma adhesion. Exp. Cell Res. 310, 282-292.

Lianidou, E. S., and Markou, A. (2011) Circulating tumor cells as emerging tumor biomarkers in breast cancer. Clin. Chem. Lab. Med. 49, 1579-1590.

Liu, Y., Jiang, P., Capkova, K., Xue, D. Ye, L., Sinha, S. C., Mackman, N., Janda, K. D., and Liu, C. (2011). Tissue factor-activated coagulation cascade in the tumor microenvironment is critical for tumor progression and an effective target for therapy. Cancer Res. 71, 6492-6502.

Lowes, L. E., Goodale, D., Keeney, M., and Allan, A. L. (2011). Image cytometry analysis of circulating tumor cells. Methods Cell Biol. 102, 261-290.

Lu, J., Steeg, P. S., Price, J. E. Krishnamurthy, S., Mani, S. A., Reuben, J., Cristofanilli, M., Dontu, G., Bidaut, L., Valero, V., Hortobagyi, G. N., and Yu, D. (2009). Breast cancer metastasis: challenges and opportunities. Cancer Res. 69, 4951-4953.

Lu, X., Mu, E., Wei, Y., Riethdorf, S., Yang, Q., Yuan, M., Yan, J., Hua, Y., Tiede, B. J., Haffty, B. G., Pantel, K., Massague, J., and Kang, Y. (2011). VCAM-1 promotes osteolytic expansion of indolent bone micrometastasis of breast cancer by engaging alpha4beta1-positive osteoclast progenitors. Cancer Cell 20, 701-714.

Matsuura, N., Narita, T., Hiraiwa, N., Hiraiwa, M., Murai, H., Iwase, T.
Funahashi, H., Imai, T., Takagi, H., and Kannagi, R. (1998). Gene expression of fucosyl- and sialyltransferases which synthesize sialyl Lewisx, the carbohydrate ligands for E-selectin, in human breast cancer. Int. J. Oncol. 12, 1157-1164.

Minn, A. J., Gupta, G. P., Siegel, P. M., Bos, P. D., Shu, W., Giri, D. D., Viale, A., Olshen, A. B., Gerald, W. L., and Massague, J. (2005). Genes that mediate breast cancer metastasis to lung. Nature 436, 518-524.

Mohammad, K. S., Javelaud, D., Fournier, P. G., Niewolna, M., McKenna, C. R., Peng, X. H. Duong, V., Dunn, L. K., Mauviel, A., and Guise, T. A. (2011). TGF-beta-RI kinase inhibitor SD-208 reduces the development and progression of melanoma bone metastases. Cancer Res. 71, 175-184.

Moreira, I. S., Fernandes, P. A., and Ramos, M. J. (2007). Vascular endothelial growth factor (VEGF) inhibition-a critical review. Anticancer Agents Med. Chem. 7, 223-245

Moretta, L., and Moretta, A. (2004). Unravelling natural killer cell function: triggering and inhibitory human NK receptors. EMBO J. 23, 255-259.

Nagrath, S., Sequist, L. V., Maheswaran, S., Bell, D. W., Irimia, D., Ulkus, L., Smith, M. R., Kwak, E. L., Digumarthy, S., Muzikansky, A., Ryan, P., Balis, U. J., Tompkins, R. G., Haber, D. A., and Toner, M. (2007). Isolation of rare circulating tumour cells in cancer patients by microchip technology. Nature 450, 1235-1239.

Nieswandt, B., Hafner, M. Echtenacher, B., and Mannel, D. N. (1999). Lysis of tumor cells by natural killer cells in mice is impeded by platelets. Cancer Res. $59,1295-1300$

Ogawa, J., Inoue, H., and Koide, S. (1996). Expression of alpha-1, 3fucosyltransferase type IV and VII genes is related to poor prognosis in lung cancer. Cancer Res. 56, 325-329.

Osborn, L., Hession, C., Tizard, R. Vassallo, C., Luhowskyj, S., ChiRosso, G., and Lobb, R. (1989). Direct expression cloning of vascular cell adhesion molecule 1, a cytokine-induced endothelial protein that binds to lymphocytes. Cell 59, 1203-1211.

Petretti, T., Schulze, B., Schlag, P. M., and Kemmner, W. (1999). Altered mRNA expression of glycosyltransferases in human gastric carcinomas. Biochim. Biophys. Acta 1428, 209-218. 
Placke, T., Orgel, M., Schaller, M., Jung, G., Rammensee, H. G., Kopp, H. G., and Salih, H. R. (2012). Platelet-derived MHC class I confers a pseudonormal phenotype to cancer cells that subverts the antitumor reactivity of natural killer immune cells. Cancer Res. 72 , 440-448.

Rana, K., Liesveld, J. L., and King, M. R. (2009). Delivery of apoptotic signal to rolling cancer cells: a novel biomimetic technique using immobilized TRAIL and E-selectin. Biotechnol. Bioeng. 102, 1692-1702.

Rana, K., Reinhart-King, C. A., and King, M. R. (2012). Inducing apoptosis in rolling cancer cells: a combined therapy with aspirin and immobilized TRAIL and Eselectin. Mol. Pharm. doi: 10.1021/ mp300073j. [Epub ahead of print].

Roberts, W. G., Whalen, P. M., Soderstrom, E., Moraski, G., Lyssikatos, J. P., Wang, H. F., Cooper, B., Baker, D. A., Savage, D., Dalvie, D., Atherton, J. A., Ralston, S., Szewc, R., Kath, J. C., Lin, J., Soderstrom, C., Tkalcevic, G., Cohen, B. D., Pollack, V., Barth, W., Hungerford, W., and Ung, E. (2005). Antiangiogenic and antitumor activity of a selective PDGFR tyrosine kinase inhibitor, CP-673, 451. Cancer Res. 65, 957-966.

Roland, C. L., Dineen, S. P., Toombs, J. E., Carbon, J. G., Smith, C. W., Brekken, R. A., and Barnett, C. C. Jr. (2010). Tumor-derived intercellular adhesion molecule-1 mediates tumor-associated leukocyte infiltration in orthotopic pancreatic xenografts. Exp. Biol. Med. (Maywood) 235, 263-270.

Rosette, C., Roth, R. B., Oeth, P., Braun, A., Kammerer, S., Ekblom, J., and Denissenko, M. F. (2005). Role of ICAM1 in invasion of human breast cancer cells. Carcinogenesis 26, 943-950.

Scher, H. I., Morris, M. J., Basch, E., and Heller, G. (2011). End points and outcomes in castrationresistant prostate cancer: from clinical trials to clinical practice. J. Clin. Oncol. 29, 3695-3704.

Shirota, K., Kato, Y., Irimura, T., Kondo, H., and Sugiyama, Y. (2001). Anti-metastatic effect of the sialyl
Lewis-X analog GSC-150 on the human colon carcinoma derived cell line KM12-HX in the mouse. Biol. Pharm. Bull. 24, 316-319.

Sierko, E., and Wojtukiewicz, M. Z. (2007). Inhibition of platelet function: does it offer a chance of better cancer progression control? Semin. Thromb. Hemost. 33, 712-721.

Slattery, M. J., and Dong, C. (2003). Neutrophils influence melanoma adhesion and migration under flow conditions. Int. J. Cancer 106 713-722.

Stevenson, J. L., Choi, S. H., and Varki, A. (2005). Differential metastasis inhibition by clinically relevant levels of heparins-correlation with selectin inhibition, not antithrombotic activity. Clin. Cancer Res. 11, 7003-7011.

Theodoropoulos, P. A., Polioudaki, H., Agelaki, S., Kallergi, G., Saridaki, Z., Mavroudis, D., and Georgoulias, V. (2010). Circulating tumor cells with a putative stem cell phenotype in peripheral blood of patients with breast cancer. Cancer Lett. 288, 99-106.

Toloudi, M., Apostolou, P., Chatziioannou, M., and Papasotiriou, I. (2011). Correlation between cancer stem cells and circulating tumor cells and their value. Case Rep. Oncol. 4, 44-54.

Toso, C., Mentha, G., and Majno, P. (2011). Liver transplantation for hepatocellular carcinoma: five steps to prevent recurrence. Am. J. Transplant. 11, 2031-2035.

Valastyan, S., and Weinberg, R. A. (2011). Tumor metastasis: molecular insights and evolving paradigms. Cell 147, 275-292.

Vermeulen, L., De Sousa E Melo, F., Richel, D. J., and Medema, J. P. (2012). The developing cancer stem-cell model: clinical challenges and opportunities. Lancet Oncol. 13 , e83-e89.

Wang, J., Cao, M. G., You, C. Z. Wang, C. L., Liu, S. L., Kai, C., and Dou, J. (2012). A preliminary investigation of the relationship between circulating tumor cells and cancer stem cells in patients with breast cancer. Cell. Mol. Biol. (Noisy-le-grand) 58(Suppl.), OL1641-OL1645.

Wang, S. (2008). The promise of cancer therapeutics targeting the
TNF-related apoptosis-inducing ligand and TRAIL receptor pathway. Oncogene 27, 6207-6215.

Wang, Q. Y., Wu, S. L., Chen, J. H., Liu, F., and Chen, H. L. (2003). Expressions of Lewis antigens in human non-small cell pulmonary cancer and primary liver cancer with different pathological conditions. J. Exp. Clin. Cancer Res. 22, 431-440.

Wang, Y., Klijn, J. G., Zhang, Y., Sieuwerts, A. M., Look, M. P., Yang, F., Talantov, D., Timmermans, M., Meijer-Van Gelder, M. E., Yu, J., Jatkoe, T., Berns, E. M., Atkins, D. and Foekens, J. A. (2005). Geneexpression profiles to predict distant metastasis of lymph-node-negative primary breast cancer. Lancet 365 , 671-679.

Wei, M., Tai, G., Gao, Y., Li, N., Huang, B., Zhou, Y., Hao, S., and Zeng, X. (2004). Modified heparin inhibits P-selectin-mediated cell adhesion of human colon carcinoma cells to immobilized platelets under dynamic flow conditions. J. Biol. Chem. 279, 29202-29210.

Weninger, W., Ulfman, L. H., Cheng, G., Souchkova, N., Quackenbush, E. J., Lowe, J. B., and Von Andrian, U. H. (2000). Specialized contributions by alpha $(1,3)$ fucosyltransferase-IV and FucT-VII during leukocyte rolling in dermal microvessels. Immunity 12 , 665-676.

Wenzel, J., Zeisig, R., Haider, W. Habedank, S., and Fichtner, I. (2010). Inhibition of pulmonary metastasis in a human MT3 breast cancer xenograft model by dua liposomes preventing intravasal fibrin clot formation. Breast Cancer Res. Treat. 121, 13-22.

Weroha, S. J., and Haluska, P. (2008). IGF-1 receptor inhibitors in clinical trials-early lessons. $J$. Mammary Gland Biol. Neoplasia 13, 471-483.

Wild, M. K., Huang, M. C., SchulzeHorsel, U., Van Der Merwe, P. A., and Vestweber, D. (2001). Affinity, kinetics, and thermodynamics of E-selectin binding to E-selectin ligand-1. J. Biol. Chem. 276, 31602-31612.

Wu, Q. D., Wang, J. H., Condron, C., Bouchier-Hayes, D., and Redmond, H. P. (2001). Human neutrophils facilitate tumor cell transendothelial migration. Am. J. Physiol. Cell Physiol. 280, C814-C822.

Yalcin, S., Kilickap, S., Portakal, O., Arslan, C., Hascelik, G., and Kutluk, T. (2010). Determination of circulating tumor cells for detection of colorectal cancer progression or recurrence. Hepatogastroenterology 57, 1395-1398.

Yang, X. S., Liu, S., Liu, Y. J., Liu, J. W., Liu, T. J., Wang, X. Q., and Yan, Q. (2010). Overexpression of fucosyltransferase IV promotes A431 cell proliferation through activating MAPK and PI3K/Akt signaling pathways. J. Cell. Physiol. 225, 612-619.

Yin, X., Rana, K., Ponmudi, V., and King, M. R. (2010). Knockdown of fucosyltransferase III disrupts the adhesion of circulating cancer cells to E-selectin without affecting hematopoietic cell adhesion. Carbohydr. Res. 345, 2334-2342.

Zacharowski, K., Otto, M., Hafner, G., Marsh, H. C. Jr., and Thiemermann, C. (1999). Reduction of myocardial infarct size with $\mathrm{sCR} 1 \mathrm{sLe}(\mathrm{x})$, an alternatively glycosylated form of human soluble complement receptor type 1 (sCR1), possessing sialyl Lewis x. Br. J. Pharmacol. 128, 945-952.

Conflict of Interest Statement: Michael R. King is a scientific advisor of CellTraffix, Inc. Jiahe $\mathrm{Li}$ has no commercial or financial relationships that could be construed as a potential conflict of interest.

Received: 29 May 2012; accepted: 07 July 2012; published online: 24 July 2012.

Citation: Li J and King MR (2012) Adhesion receptors as therapeutic targets for circulating tumor cells. Front. Oncol. 2:79. doi: 10.3389/fonc.2012.00079 This article was submitted to Frontiers in Cancer Molecular Targets and Therapeutics, a specialty of Frontiers in Oncology.

Copyright (c) 2012 Li and King. This is an open-access article distributed under the terms of the Creative Commons Attribution License, which permits use, distribution and reproduction in other forums, provided the original authors and source are credited and subject to any copyright notices concerning any thirdparty graphics etc. 